Reprod. Nutr. Dévelop., 1987, 27 (1 B), 271-272.

\title{
Influence du niveau des apports azotés sur l'évolution de la digestion chez la vache à proximité du vêlage
}

\author{
M. DOREAU, B. RÉMOND
}

Laboratoire de la Lactation,

I.N.R.A., Theix, 63122 Ceyrat, France.

Summary. The decrease in organic matter, nitrogen and crude fiber digestibility of a diet of constant composition between late pregnancy and early lactation was greater when the diet had a low crude protein content $(12 \%)$ than when it had a higher content $(15 \%)$. Lactation involved a decrease in rumen ammonia and the acetate/propionate ratio and an increase in the duodenal $\mathrm{N} / \mathrm{N}$ intake ratio.

La diminution de la digestibilité de la ration au tout début de la lactation, et la forte réduction concomitante de la teneur en ammoniac $\left(\mathrm{NH}_{3}\right)$ du liquide du rumen (Doreau et Rémond, 1982) nous ont incités à étudier le rôle de la teneur en azote de la ration sur la digestion pendant cette période.

Matériel et méthodes. Quatre vaches laitières équipées de canules du rumen et du duodénum proximal et, pour deux d'entre elles, de l'iléon terminal, ont été utilisées. Elles produisaient en moyenne $21 \mathrm{~kg}$ de lait par jour dans le premier mois de lactation. Elles ont reçu une ration de composition constante constituée d'ensilage de maïs, de pulpes sèches de betteraves, de maïs grain et de tourteau de soja dans les proportions de $65,15,5$ et $15 \%$ de la matière sèche (MS) pour les 2 vaches qui portaient une canule de l'iléon (ration riche en azote $H$ ) et de 65,15 , 14 et $6 \%$ pour les 2 autres (ration $B$ ). Les concentrations en matière organique (MO), en azote (N), et en cellulose brute (CB) étaient respectivement de $93,7 \%$, $2,38 \%$ et $16,0 \%$, et de $92,8 \%, 1,97 \%$ et $15,9 \%$. Ces rations étaient offertes en mélange, deux fois par jour (7 et $18 \mathrm{~h}$ ), à raison de $1,7 \mathrm{~kg}$ de MS par $100 \mathrm{~kg}$ de poids vif pendant la gestation et à volonté à partir du vêlage.

On a déterminé à 4 périodes ( 2 semaines avant et $2,3,5$ semaines après le vêlage) la digestibilité de la ration et de ses principaux constituants par collecte totale des fèces pendant 5 jours, et le flux des digesta aux niveaux duodénal et iléal par utilisation simultanée d'oxyde de chrome et de polyéthylène glycol (18 prélèvements en période diurne). Dans le liquide du rumen, on a dosé les teneurs en $\mathrm{NH}_{3}$ avant et 1,2 et $4 \mathrm{~h}$ après la distribution des aliments du matin. Dans ce dernier échantillon, le $\mathrm{pH}$, la concentration et la composition des acides gras volatils (AGV) ont été mesurés pour les vaches recevant la ration $H$.

Résultats et discussion. La digestibilité des raciuıs aimmue entre la tin de la gestation et le début de la lactation, plus fortement avec le régime B qu'avec le régime $H$, en même proportion pour $N$ et $C B$ que pour MO (tabl. 1). Un effet similaire du niveau azoté avait été observé par Tyrrell et al. (1982) comparant des vaches en lactation et taries. L'augmentation des quantités ingérées et la distribution à volonté après vêlage n'expliquent probablement qu'une partie de la variation liée à l'état physiologique. La part du rumen dans la digestion de la MO diminue entre la gestation et la lactation pour le régime $B$, mais reste constante pour le régime $H$. La digestion dans le gros intestin est toujours très limitée : moins de 
$10 \%$ de la MO ingérée. Entre les semaines $-2,2,3$, et 5 , le pH diminue $(6,67$; $6,24 ; 6,38$ et 6,53$)$, ainsi que la proportion d'acétate $(63,9 ; 60,9 ; 61,9$ et $60,7 \%)$, celle de propionate augmente $(18,6 ; 21,0 ; 20,0$ et $22,0 \%)$, celle de butyrate ne variant pas $(13,0 ; 13,5 ; 13,3$ et $12,7 \%)$, de même que la concentration en AGV totaux $(97,6 ; 104,3 ; 108,9$ et $102,4 \mathrm{mM} / \mathrm{I})$.

TABL. 1. - Effet de la concentration en azote de la ration et du stade physiologique sur la digestion chez la vache.

\begin{tabular}{|c|c|c|c|c|c|c|c|c|}
\hline Régime & & & & & & & & \\
\hline Semaine avant $(-)$ ou après vêlage & -2 & 2 & 3 & 5 & -2 & 2 & 3 & 5 \\
\hline Quantités ingérées : $\mathrm{MO} / \mathrm{kg} / \mathrm{j}$ ) & 9,3 & 10,0 & 11,0 & 12,2 & 9,0 & 10,5 & 10,8 & 13,2 \\
\hline$\stackrel{N}{N}(\mathrm{~g} / \mathrm{j})$ & 206 & $\begin{array}{l}214 \\
728\end{array}$ & 224 & $\begin{array}{r}249 \\
709\end{array}$ & $\begin{array}{l}234 \\
772\end{array}$ & $\begin{array}{l}273 \\
741\end{array}$ & $\begin{array}{l}283 \\
718\end{array}$ & $\begin{array}{l}316 \\
746\end{array}$ \\
\hline Digestibilité apparente (\%) $\mathrm{MO}_{\mathrm{N}}$ & $\begin{array}{l}79,1 \\
64,3\end{array}$ & $\begin{array}{l}72,8 \\
57,5\end{array}$ & $\begin{array}{l}70,9 \\
55,4\end{array}$ & 53,9 & 65,8 & 61,4 & $\begin{array}{l}/ 1,8 \\
61,3\end{array}$ & $\begin{array}{l}74,6 \\
64,2\end{array}$ \\
\hline $\mathrm{CB}$ & 70,3 & 64,4 & 61,0 & 61,0 & 70,4 & 64,8 & 62,1 & 63,2 \\
\hline MO digérée dans le rumen $(\mathrm{kg} / \mathrm{j})$ & 5,1 & 5,6 & 5,2 & 5,5 & 3,9 & 5,1 & 5,2 & 5,8 \\
\hline MO digérée dans l'intestin grêle $(\mathrm{kg} / \mathrm{j})$ & - & - & - & - & 2,8 & 1,8 & 2,2 & 2,9 \\
\hline Flux ANA duodénal $\{\mathbf{g} / \mathbf{j}\rangle$ & 216 & 213 & 280 & 307 & 206 & 267 & 287 & 328 \\
\hline Flux ANA iléal & - & - & - & - & 77 & 103 & 101 & 128 \\
\hline Teneur en $\mathrm{NH}_{3}(\mathrm{mg} / /)\left\{\begin{array}{l}\text { avant repas } \ldots \\
1 \text { h après repas }\end{array}\right.$ & $\begin{array}{l}102 \\
200\end{array}$ & $\begin{array}{r}75 \\
133\end{array}$ & $\begin{array}{l}49 \\
95\end{array}$ & $\begin{array}{r}39 \\
105\end{array}$ & $\begin{array}{l}171 \\
277\end{array}$ & $\begin{array}{r}62 \\
122\end{array}$ & $\begin{array}{r}74 \\
140\end{array}$ & $\begin{array}{r}88 \\
163\end{array}$ \\
\hline
\end{tabular}

La diminution de la digestibilité de l'azote après le vêlage est peu liée à sa digestibilité intestinale apparente $(66,2 \%$ en fin de gestation, $61,9 \%$ en début de lactation). Les teneurs en $\mathrm{NH}_{3}$ du liquide du rumen sont toujours plus faibles en lactation qu'en gestation, en particulier avec le régime $\mathrm{B}$. Ceci peut correspondre à une moindre production d'urée dans le foie en raison des besoins en acides aminés de la mamelle et d'une utilisation maximale de l'azote dans le rumen grâce à un recyclage important. D'ailleurs, le rapport entre l'azote non ammoniacal (ANA) duodénal et l'azote ingéré s'accroît, passant en moyenne de 1,00 à 1,14 pour le lot $B$ et de 0,86 à 1,02 pour le lot $H$. Cependant, comme dans un essai précédent (Doreau et al., 1985), il n'y a pas de différence significative de digestibilité, de teneur en $\mathrm{NH}_{3}$ du liquide du rumen et du rapport ANA duodénal / $\mathrm{N}$ ingéré entre les semaines 2, 3 et 5 après le velage, alors que les quantités ingérées s'accroissent et que la quantité de protéines exportée dans le lait diminue (en moyenne 786, 730 et $671 \mathrm{~g} / \mathrm{j}$ ). Le flux d'azote passant par l'iléon terminal est toujours proche du flux d'azote fécal.

En conclusion, il semble que l'effet de l'apport azoté sur les phénomènes digestifs soit plus important en début de lactation qu'en fin de gestation, en liaison avec une modification du métabolisme azoté.

Doreau M., Rémond B. 1982. Reprod. Nutr. Dévelop., 22, 307-324.

Doreau M., Delacroix A., Rémond B., 1985. Reprod. Nutr. Dévelop., 25, 779.

Tyrrell H. F., Haaland G. L., Moe P. W., Brown A. C. G., 1982. In A. Ekern, F. Sundstol. Energy metabolism of farm animals, 14-17, Ed. Agric. Univ. Norway. 